University of Nebraska - Lincoln

DigitalCommons@University of Nebraska - Lincoln

2012

\title{
Continental-scale validation of MODIS-based and LEDAPS Landsat ETM+ atmospheric correction methods
}

Junchang Ju

South Dakota State University

David P. Roy

South Dakota State University, david.roy@sdstate.edu

Eric Vermote

University of Maryland

Jeffrey Masek

NASA Goddard Space Flight Center

Valeriy Kovalskyy

South Dakota State University

Follow this and additional works at: https://digitalcommons.unl.edu/nasapub

Part of the Physical Sciences and Mathematics Commons

Ju, Junchang; Roy, David P.; Vermote, Eric; Masek, Jeffrey; and Kovalskyy, Valeriy, "Continental-scale validation of MODIS-based and LEDAPS Landsat ETM+ atmospheric correction methods" (2012). NASA Publications. 62.

https://digitalcommons.unl.edu/nasapub/62

This Article is brought to you for free and open access by the National Aeronautics and Space Administration at DigitalCommons@University of Nebraska - Lincoln. It has been accepted for inclusion in NASA Publications by an authorized administrator of DigitalCommons@University of Nebraska - Lincoln. 


\title{
Continental-scale validation of MODIS-based and LEDAPS Landsat ETM+ atmospheric correction methods
}

\author{
Junchang Ju ${ }^{\mathrm{a}, *}$, David P. Roy ${ }^{\mathrm{a}}$, Eric Vermote ${ }^{\mathrm{b}}$, Jeffrey Masek ${ }^{\mathrm{c}}$, Valeriy Kovalskyy ${ }^{\mathrm{a}}$ \\ a Geographic Information Science Center of Excellence, South Dakota State University, Brookings, SD 57007, USA \\ b Department of Geography, University of Maryland, College Park, MD 20742, USA \\ c Biospheric Sciences Branch, NASA Goddard Space Flight Center, Greenbelt, MD 20771, USA
}

\section{A R T I C L E I N F O}

\section{Article history:}

Received 10 April 2011

Received in revised form 9 December 2011

Accepted 10 December 2011

Available online $\mathrm{xxxx}$

\section{Keywords:}

Landsat

MODIS

Atmospheric correction

Web-enabled Landsat Data (WELD)

Landsat Ecosystem Disturbance Adaptive

Processing System (LEDAPS)

\begin{abstract}
A B S T R A C T
The potential of Landsat data processing to provide systematic continental scale products has been demonstrated by several projects including the NASA Web-enabled Landsat Data (WELD) project. The recent free availability of Landsat data increases the need for robust and efficient atmospheric correction algorithms applicable to large volume Landsat data sets. This paper compares the accuracy of two Landsat atmospheric correction methods: a MODIS-based method and the Landsat Ecosystem Disturbance Adaptive Processing System (LEDAPS) method. Both methods are based on the 6SV radiative transfer code but have different atmospheric characterization approaches. The MODIS-based method uses the MODIS Terra derived dynamic aerosol type, aerosol optical thickness, and water vapor to atmospherically correct ETM+ acquisitions in each coincident orbit. The LEDAPS method uses aerosol characterizations derived independently from each Landsat acquisition and assumes a fixed continental aerosol type and uses ancillary water vapor. Validation results are presented comparing ETM + atmospherically corrected data generated using these two methods with AERONET corrected ETM + data for $9510 \mathrm{~km} \times 10 \mathrm{~km} 30 \mathrm{~m}$ subsets, a total of nearly 8 million $30 \mathrm{~m}$ pixels, located across the conterminous United States. The results indicate that the MODIS-based method has better accuracy than the LEDAPS method for the ETM+ red and longer wavelength bands.
\end{abstract}

(c) 2012 Elsevier Inc. All rights reserved.

\section{Introduction}

The impact of the atmosphere is variable in space and time and is usually considered as requiring correction for quantitative remote sensing applications (Liang et al., 2001; Ouaidrari \& Vermote, 1999). The recent free availability of the United States (U.S.) Landsat data archive (Woodcock et al., 2008) has stimulated the development of large area Landsat data processing activities. The Web-enabled Landsat Data (WELD) project is systematically generating $30 \mathrm{~m}$ composited Landsat Enhanced Thematic Mapper Plus (ETM+) mosaics of the conterminous United States (CONUS) and Alaska with the aim of providing consistent $30 \mathrm{~m}$ data that can be used to derive land cover as well as geophysical and biophysical products (Roy et al., 2010). The most recent Version 1.5 WELD products include the top of atmosphere (TOA) reflectance for each of the six reflective wavelength Landsat ETM + bands (Roy et al., 2011, http://landsat.usgs.gov/ WELD.php). The planned Version 2.0 WELD products will be corrected for atmospheric effects to provide land surface reflectance for the approximately 11,000 million and 3100 million $30 \mathrm{~m}$ Landsat pixels encompassing the CONUS and Alaska respectively. Consistent

\footnotetext{
* Corresponding author. Tel.: +1605 6885856.

E-mail address: junchang.ju@sdstate.edu (J. Ju).
}

surface reflectance data are needed to derive geophysical and biophysical products (Vermote et al., 2002). In this paper the accuracy of two state-of-the-practice atmospheric correction methods suitable for systematic application to large volume Landsat data sets such as the WELD data is assessed.

A number of Landsat atmospheric correction methodologies have been developed. Empirical correction methods are mostly variants of the dark-object subtraction (DOS) method (Chavez, 1996; Song \& Woodcock, 2003). In the DOS approach, atmospheric path radiance is assumed to be equal to the radiance sensed over dark objects, such as dense dark vegetation or deep clear water. After identification, the dark object reflectance is subtracted from the entire image for each TOA reflective band. Dark object subtraction based approaches do not correct for variations in the atmospheric scattering and absorbing constituents across the image or account for multiple scattering. Radiative transfer based atmospheric correction approaches typically do not have these issues as they model the propagation of solar electromagnetic radiation through the atmosphere. Although radiative transfer based approaches are amenable to systematic large volume satellite processing they do require temporally and spatially explicit atmospheric characterization data (Vermote et al., 2002).

In this paper, two state-of-the-practice radiative transfer based Landsat ETM+ atmospheric correction methods are considered: the 
Landsat Ecosystem Disturbance Adaptive Processing System (LEDAPS) method (Masek et al., 2006) and a new MODIS-based method described herein. Both methods use the 6SV radiative transfer code (available at http://6s.ltdri.org/) which has an accuracy better than $1 \%$ over a range of atmospheric stressing conditions (Kotchenova et al., 2006). The two methods differ in the way that they characterize the atmosphere, with the greatest difference in the aerosol characterization. The MODISbased method uses MODIS Terra derived aerosol optical thickness and dynamic aerosol type to atmospherically correct Landsat ETM+ acquisitions in each coincident orbit. The LEDAPS method derives the aerosol optical thickness from each Landsat acquisition and independently corrects each acquisition assuming a fixed continental aerosol type. These two correction methods and the data they use are described in more detail below. As there are no ground measured surface reflectance datasets distributed across the United States with sensor footprints and spectral bandpasses similar to Landsat, the accuracies of the MODIS-based and LEDAPS atmospherically corrected Landsat $\mathrm{ETM}+$ surface reflectance data are quantified by comparison with $\mathrm{ETM}+$ surface reflectance derived independently using the 6SV radiative transfer code parameterized with AERONET sun-photometer retrievals (Dubovik, et al., 2002; Holben et al., 1998). The AERONET data typically enable radiative transfer based atmospheric correction to $2 \%$ accuracy and have been used previously to validate satellite surface reflectance products (Kotchenova et al., 2006; Vermote et al., 2002). The comparisons are undertaken for $10 \mathrm{~km} \times 10 \mathrm{~km}$ Landsat ETM+ spatial subsets centered on AERONET sites across the conterminous United States, for a year of Landsat ETM + observations, to provide a comprehensive assessment over a range of land surfaces and atmospheric conditions.

\section{Data and pre-processing}

\subsection{Landsat $E T M+$ data}

Level 1 terrain corrected (L1T) ETM + data were obtained from the USGS EROS Landsat Project. The Level $1 \mathrm{~T}$ processing includes radiometric correction, systematic geometric correction, precision correction using ground control chips, and the use of a digital elevation model to correct parallax error due to local topographic relief. The CONUS L1T geolocation error is less than $30 \mathrm{~m}$ (Lee et al., 2004). In this study the six $30 \mathrm{~m}$ reflective ETM + wavelength bands were used: blue $(0.45-0.52 \mu \mathrm{m})$, green (0.53-0.61 $\mu \mathrm{m})$, red $(0.63-0.69 \mu \mathrm{m})$, near-infrared $(0.78-0.90 \mu \mathrm{m})$, and two middle-infrared bands (1.55-1.75 $\mu \mathrm{m}$ and $2.09-2.35 \mu \mathrm{m})$. The six bands were converted to top of atmosphere (TOA) reflectance using the best available ETM + calibration coefficients and standard correction formulae (Chander et al., 2009). A bit-packed band saturation mask was created to define which bands of each pixel were saturated (Roy et al., 2010) and two 30 m cloud masks were generated: the Automated Cloud Cover Assessment (ACCA) mask (Irish et al., 2006) and a classification tree based cloud mask (Roy et al., 2010).

The 7665 Landsat ETM+ L1T scenes acquired over the conterminous United States (CONUS) in the period December 1st, 2007 to November 30th, 2008 that were used to generate the Version 1.5 annual 2008 WELD composite (http://weld.cr.usgs.gov) were considered. These data were compared to the geographic locations of the 119 CONUS AERONET sun-photometer sites. Only Landsat acquisitions encompassing an AERONET site with reliable cloud-free AERONET retrievals on the day of the Landsat 7 overpass were selected. This provided 82 Landsat ETM+ acquisitions at 26 AERONET sites encompassing surfaces varying from dark vegetation to highly reflective soil (Fig. 1). From these, spatial subsets of $10 \mathrm{~km} \times 10 \mathrm{~km}$ centered on the AERONET sites were extracted. A total of 95 Landsat ETM + spatial subsets were extracted throughout the year (Fig. 2) including dates with snow and with a range of atmospheric conditions.

\subsection{Atmospheric characterization data}

The atmospheric characterization data sources for the LEDAPS, MODIS-based and AERONET atmospheric corrections of the Landsat $\mathrm{ETM}+$ subsets are described below.

\subsubsection{LEDAPS atmospheric characterization data}

The LEDAPS algorithm uses ancillary sea level atmospheric pressure and water vapor characterization obtained from the National Centers for Environmental Prediction (NCEP) and the National Center for Atmospheric Research (NCAR), and ozone from the NASA Earth Probe Total Ozone Mapping Spectrometer (EP TOMS) (Masek et al., 2006). The ozone EP TOMS data are defined daily at $1^{\circ}$ spatial resolution. The sea level atmospheric pressure and water vapor data are defined every $6 \mathrm{~h}$ at $2.5^{\circ}$ spatial resolution and their values are temporally linearly interpolated to the Landsat overpass time. A static global $0.05^{\circ}$ digital elevation model was used in the LEDAPS code to adjust the atmospheric pressure from sea level to surface level. This was achieved by multiplying the sea level pressure with the negative exponent of the quotient of the digital elevation and an $8000 \mathrm{~m}$ scale height (Vermote \& Saleous, 2006).

The aerosol optical thickness (AOT) is retrieved independently from each Landsat acquisition using the Kaufman et al. (1997) dense dark vegetation (DDV) approach and assuming a fixed "continental" aerosol model. LEDAPS DDV pixels are defined as those pixels with TOA reflectance $\bar{\rho}_{7}^{\text {TOA }}<0.15$. The mean ETM + band 1 TOA reflectance, $\bar{\rho}_{1}^{\text {TOA }}$, and the mean band 7 surface reflectance, $\bar{\rho}_{7}^{s}$, for DDV pixels falling within $1.2 \mathrm{~km}$ grids (i.e. 4030 -m Landsat pixels) are computed and used to invert for the AOT by using 6S and iteratively varying AOT to atmospherically correct $\bar{\rho}_{1}^{\text {TOA }}$ until $\bar{\rho}_{1}^{s} \approx 0.33 \bar{\rho}_{7}^{s}$. If valid DDV targets are not found within a $1.2 \mathrm{~km}$ grid cell, the AOT value is interpolated by averaging neighboring values within a $7 \mathrm{~km}$ window. A default AOT (0.06) is used to fill larger gaps. All the atmospheric characterization parameters are resampled by bilinear interpolation to common $1.2 \mathrm{~km}$ grid cells.

\subsubsection{MODIS atmospheric characterization data}

The Landsat 7 ETM + and MODIS Terra systems are in the same polar orbit, with Landsat ETM+ observations occurring approximately 25 min before MODIS Terra nadir observations. The MODIS-based method uses the atmospheric characterization data used to correct the MODIS Terra TOA reflectance to surface reflectance (Vermote et al., 2002). This MODIS-based atmospheric characterization is assumed to be the same as for the approximately 25 min earlier Landsat overpass, except for rapidly moving atmospheres.

The MODIS Terra atmospheric characterization data is defined at $0.05^{\circ}$ for each MODIS Level 2 granule (approximately $2000 \mathrm{~km}$ along track and $2300 \mathrm{~km}$ along scan). The aerosol optical thickness at $550 \mathrm{~nm}$, and the aerosol type (low absorption smoke, high absorption smoke, polluted urban, and clean urban types) are derived dynamically from the MODIS shortwave visible ocean and land bands using an improved non-linear version of the Kaufman et al. (1997) dense dark vegetation methodology (Vermote \& Kotchenova, 2008). The water vapor is derived directly from the MODIS near-infrared water vapor bands (typical accuracy 5-10\%) (Vermote \& Kotchenova, 2008), sea-level atmospheric pressure is defined by NCEP/NCAR 6-hourly Reanalysis data, and NCEP ozone is derived from NASA NOAA Total Operational Vertical Sounder (TOVS) ozone retrievals (typical accuracy $0.02 \mathrm{~cm} \cdot \mathrm{atm}$ ). The one arc-second resolution ASTER digital elevation model (http://asterweb.jpl.nasa.gov/gdem.asp) is used to adjust the atmospheric pressure from sea level to surface level in the same manner as the LEDAPS pressure adjustment.

Fig. 3 shows an example of one day of the $0.05^{\circ}$ MODIS Terra derived aerosol optical thickness (top) and aerosol type (bottom) over the conterminous United States (CONUS). A total of three MODIS day time overpasses of the CONUS were sensed. The Landsat ETM+ sensor has approximately the same nadir ground track as MODIS 


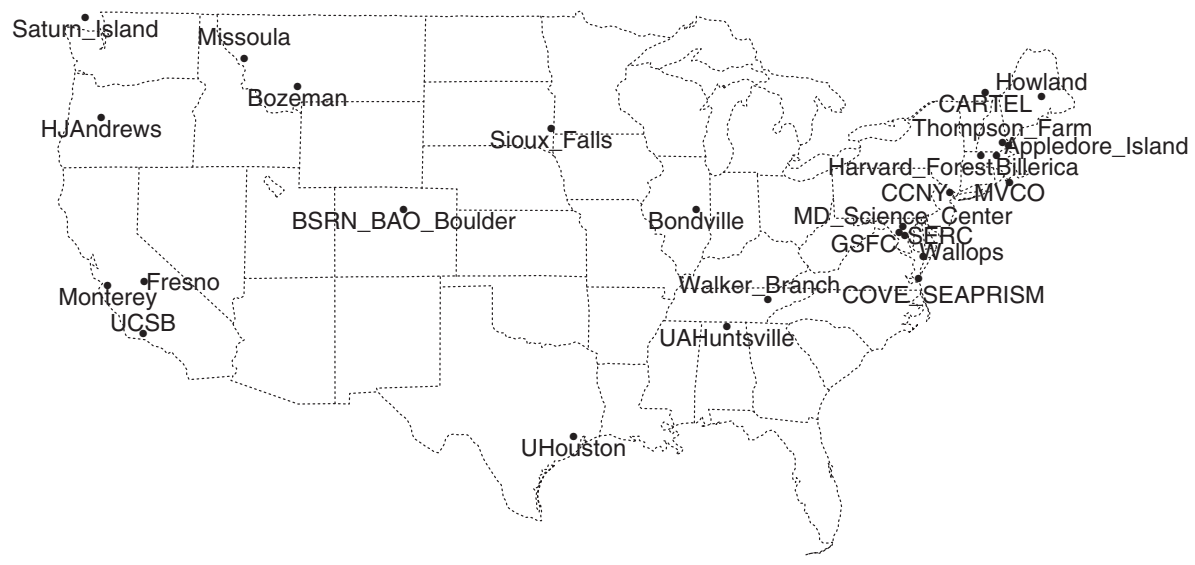

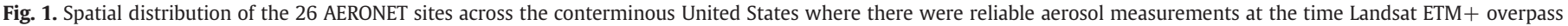
during the period December 12007 to November 302008.

Terra but because of the narrow ETM $+15^{\circ}$ field of view it only senses a swath approximately $185 \mathrm{~km}$ across scan.

\subsubsection{AERONET atmospheric characterization data}

The Aerosol Robotic Network (AERONET) is a network of globally distributed ground-based sun and sky scanning radiometers that provide near-continuous daytime measurements of spectral aerosol optical thickness, water vapor, and inversion aerosol products (Dubovik et al., 2002; Holben et al., 1998). The AERONET data obtained from the AERONET web site (http://aeronet.gsfc.nasa.gov/) include aerosol optical thickness in 7-8 narrow spectral bands with center wavelengths from $0.340 \mu \mathrm{m}$ to $1.640 \mu \mathrm{m}$, aerosol volume size distribution in 22 bins from $0.05 \mu \mathrm{m}$ to $15 \mu \mathrm{m}$, aerosol complex refractive index (real and imaginary components) in four spectral bands with center wavelengths of $0.440 \mu \mathrm{m}, 0.657 \mu \mathrm{m}, 0.871 \mu \mathrm{m}$ and $1.018 \mu \mathrm{m}$, the degree of particle sphericity, and column water vapor $\left(\mathrm{g} / \mathrm{cm}^{2}\right)$. The AERONET data include measurement time and date information with three data quality levels: Level 1.0 (unscreened), Level 1.5 (cloud-screened), and Level 2.0 (cloud-screened and qualityassured). The Level 2.0 AERONET data are of higher quality but the retrievals are temporally more sparse than the Level 1.5 data. Over the 119 CONUS AERONET sites, reliable aerosol volume size distribution, complex refractive index and the degree of particle sphericity retrievals were not always available at Level 2.0. Consequently, in this study, Level 2.0 aerosol optical thickness retrievals and Level 1.5

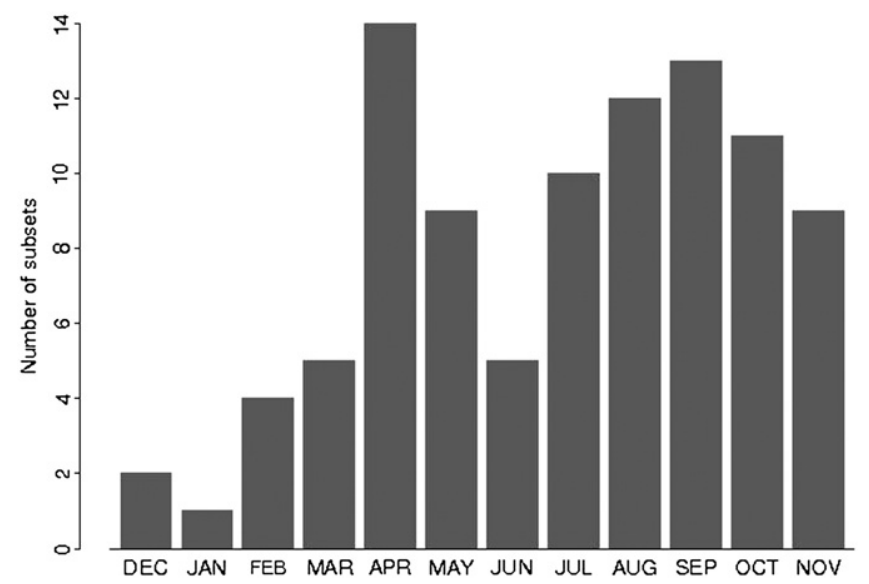

Fig. 2. The monthly number of Landsat ETM $+10 \mathrm{~km} \times 10 \mathrm{~km}$ subsets at the 26 AERONET sites (Fig. 1) where there were co-incident, reliable aerosol measurements during the period December 12007 to November 302008 (an annual total of $9510 \mathrm{~km} \times 10 \mathrm{~km}$ subsets). aerosol volume size distribution, complex refractive index, and degree of particle sphericity retrievals were used.

The aerosol optical thickness (AOT) was derived as the average of the two closest AERONET AOT Level 2.0 retrievals made immediately before and after the Landsat overpass time and no more than $30 \mathrm{~min}$ apart. Similarly, the water vapor was derived as the average of the two AERONET water vapor retrievals associated with these two closest AOT retrievals. The aerosol volume size distribution, complex refractive index, and degree of particle sphericity retrievals were selected as the closet Level 1.5 set occurring the day of Landsat acquisition with a solar zenith greater than $50^{\circ}$ as they are most reliably retrieved when sky radiance measurements are made over a wide range of scattering angles (Dubovik, et al., 2002). In order to maximize the quality of the AERONET data, only data with a $0.47 \mu \mathrm{m}$ imaginary component of the refractive index less than 0.015 were used. This threshold was arbitrarily selected but purposefully quite conservative. AERONET retrievals have limitations at low to medium optical thickness and CONUS aerosols usually have low absorption (unlike for example, African savanna biomass burning aerosols) and imaginary refractive index values greater than 0.015 are in general suspect in those conditions as shown by robustly determined climatological aerosol models (Dubovik et al., 2002).

The surface atmospheric pressure and atmospheric ozone data were defined as the average of the LEDAPS and the MODIS values for the AERONET site location. The atmospheric pressure and ozone data used by the LEDAPS and the MODIS-based methods are essentially from the same sources, but they are slightly different caused by resampling to different spatial resolutions, so an average provides an unbiased estimate for the subsequent comparison.

\section{Methods}

\subsection{Atmospheric correction}

The $30 \mathrm{~m}$ Landsat ETM+ TOA reflectance for each of the 95 $10 \mathrm{~km} \times 10 \mathrm{~km}$ spatial subsets was atmospherically corrected independently using the AERONET, LEDAPS, and MODIS-based atmospheric characterizations using 6SV (Kotchenova et al., 2006). The atmospheric correction assumes that the surface is Lambertian and infinite, and models the TOA reflectance for a given sun-view geometry and spectral band (Kaufman \& Sendra, 1988) as:

$\rho^{T O A}=\rho_{a t m}+\frac{T_{d} T_{u} \rho^{S}}{1-S_{a t m} \rho^{S}}$

where $\rho^{T O A}$ is the TOA reflectance, $\rho_{a t m}$ is the atmospheric intrinsic reflectance, $T_{d}$ is the downward atmospheric transmission in the 

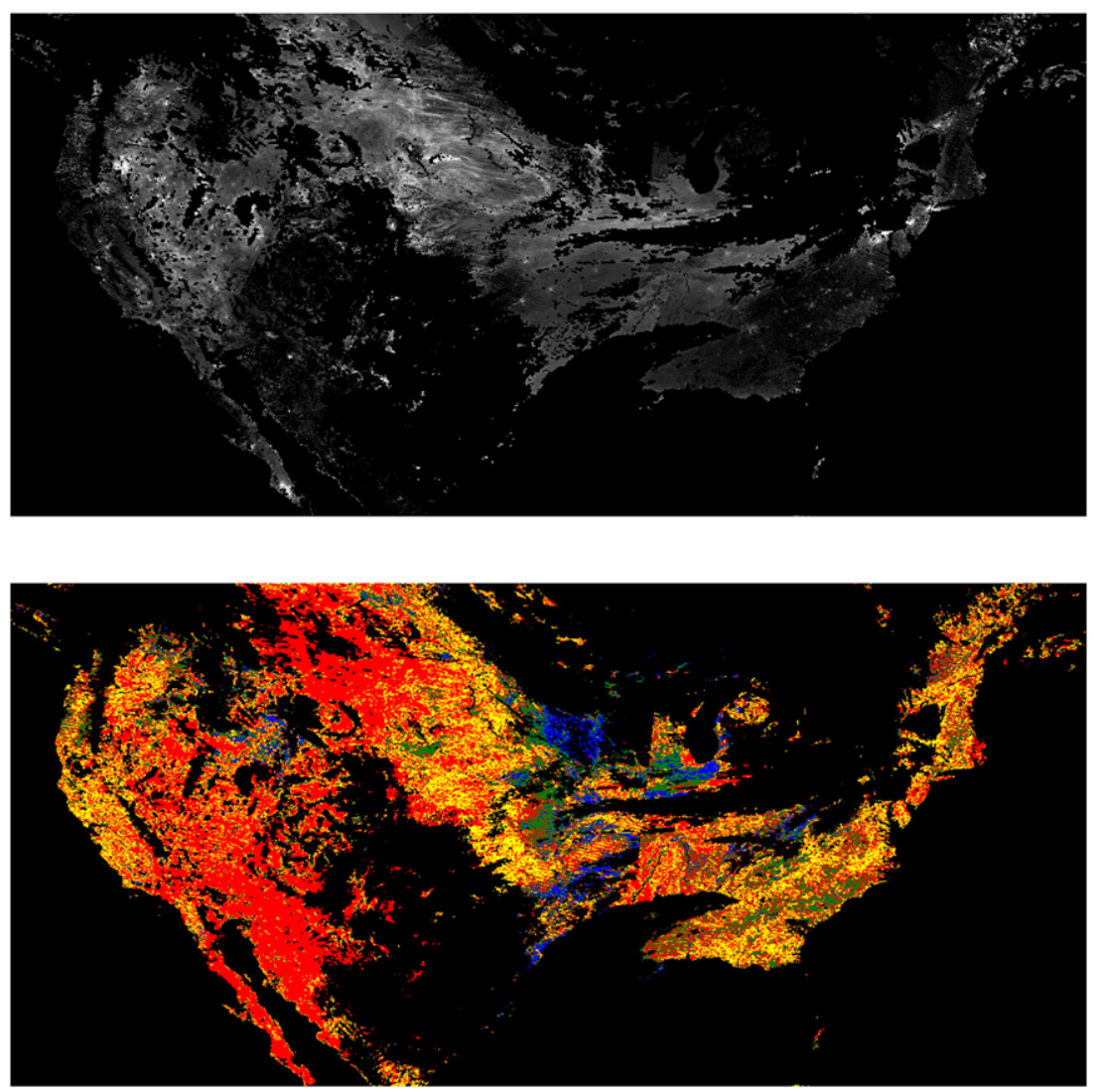

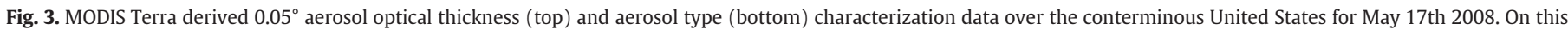

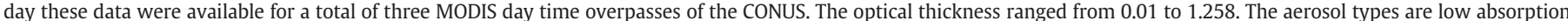
smoke (blue), high absorption smoke (green), polluted urban (yellow), and clean urban (red). Fill values are shown as black.

direction of light propagation from the TOA to the surface, $T_{u}$ is the upward atmospheric transmission in the direction of light propagation from the surface to the sensor, $\rho^{s}$ is the surface reflectance, and $s_{a t m}$ is the atmospheric spherical albedo. Note, that the effect of gaseous transmission has been omitted from Eq. (1) for simplicity. When atmospheric characterization data are available, $\rho_{a t m}, T_{d}, T_{u}$, and $s_{a t m}$, for a given sun-view geometry, can be computed using 6SV and the surface reflectance $\rho^{s}$ derived. In this study, the geometry used was set, as for the LEDAPS code, using the Landsat ETM+ scene center solar zenith, the relative azimuth set as the scene center solar azimuth, and an arbitrary $3.5^{\circ}$ view zenith (half way from nadir to the $\mathrm{ETM}+$ swath edge).

\subsubsection{AERONET atmospheric correction}

The $30 \mathrm{~m}$ Landsat ETM + TOA reflectance was corrected using the AEORNET atmospheric characterization data specific to each ETM+ subset. The AERONET data were input into the 6SV radiative code which was run once per subset to return for each of the six reflective bands three coefficients that were used to generate surface reflectance for each band as:

$\rho^{s}=\frac{\rho^{T O A} a-b}{\left(\rho^{T O A} a-b\right) c+1}$

where $\rho^{s}$ and $\rho^{T O A}$ are the surface and TOA reflectance respectively, and the coefficients $a, b, c$ are defined from Eq. (1) as $a=\frac{1}{T_{d} T_{u}}$, $b=\frac{\rho_{a t m}}{T_{d} T_{u}}$, and $c=s_{a t m}$.

The resulting AERONET corrected surface reflectance data are considered to provide the surface reflectance "truth", since the greatest uncertainty in atmospheric correction comes from the aerosol characterization and the AERONET provides state-of-the-art aerosol characterization.

\subsubsection{LEDAPS and MODIS-based atmospheric correction}

The $30 \mathrm{~m}$ Landsat ETM+ TOA reflectance was atmospherically corrected independently using the LEDAPS and MODIS-based atmospheric characterization data. This was straightforward for the LEDAPS code, which is fully automated and is described in Masek et al. (2006), although care was needed to ensure that the saturated labeled pixels were read correctly.

The MODIS-based atmospheric correction required some additional development. A multidimensional look-up table was generated for each of the four aerosol types by forward modeling with 6SV and using the Landsat ETM+ reflective wavelength band characteristics. Each look up table returns four atmospheric correction coefficients per ETM+ reflective wavelength band. Each look-up table was parameterized by ETM+ band number, aerosol optical thickness (22 levels), surface atmospheric pressure (7 levels), and sun-view geometry (5527 levels covering $0^{\circ}$ to $84^{\circ}$ sun zeniths, $0^{\circ}$ to $69.589^{\circ}$ view zeniths, and with the azimuthal plane sampled at constant $4^{\circ}$ scattering angle interval). The ozone, water vapor absorption and other gases absorptions were calculated using empirical fits based on 6SV forward modeling.

For each Landsat ETM+ band the four atmospheric correction coefficients $\rho_{a t m} / T_{d}, T_{d}, T_{u}$, and $s_{a t m}$ (defined in Eq. 1) were derived using the $0.05^{\circ}$ MODIS atmospheric characterization data input into the look up table. Fig. 4 (top) illustrates the $\rho_{a t m} / T_{d}$ values in the Landsat ETM + blue band $(0.45-0.52 \mu \mathrm{m})$ for the conterminous United States for May 17th, 2008 computed for the geometry of a Landsat acquisition acquired over path 15 and row 33 near the Chesapeake Bay in Maryland. 

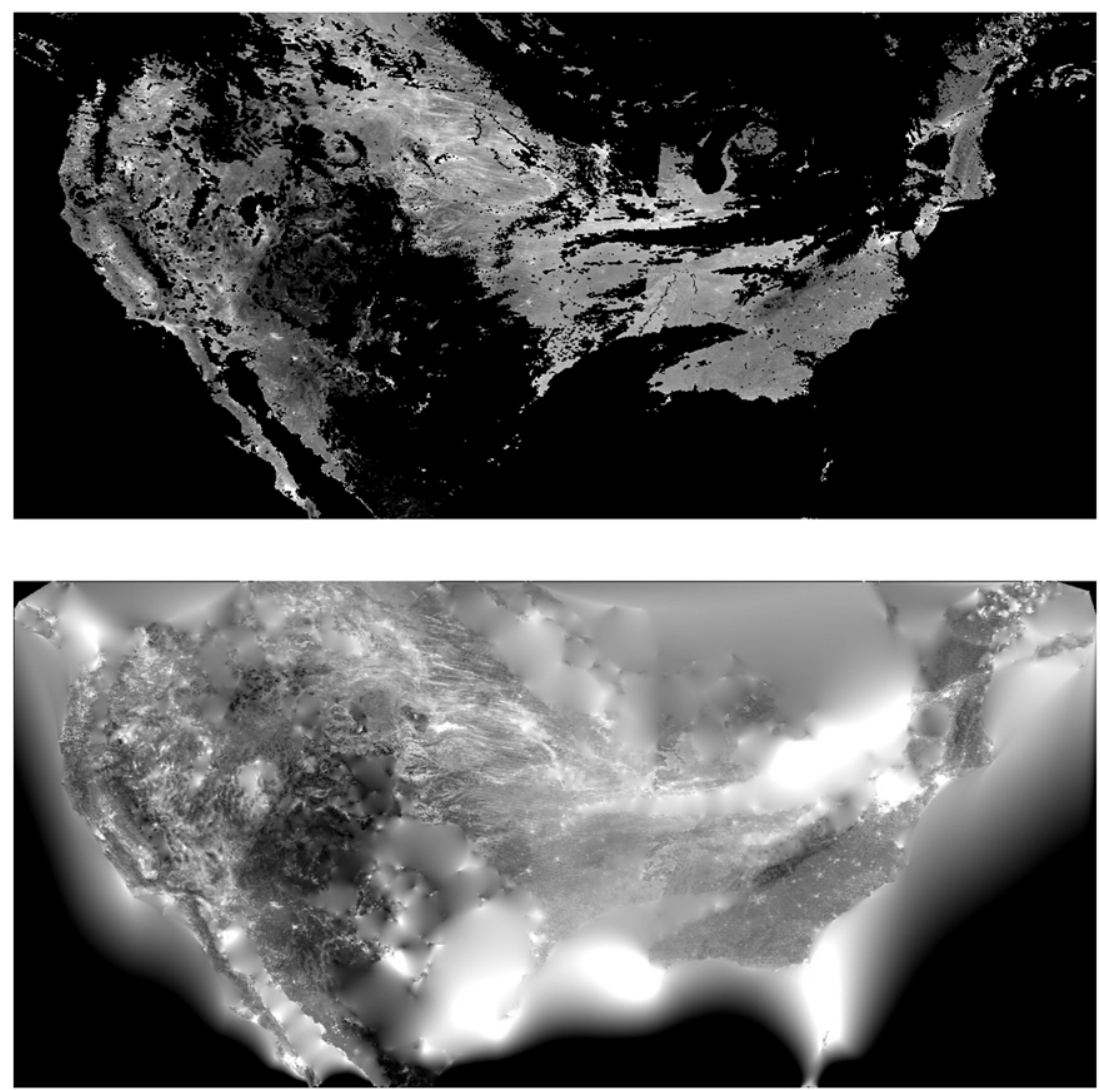

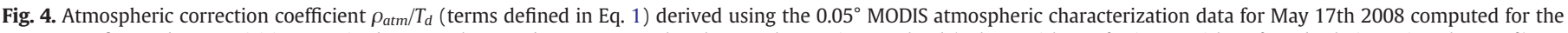
geometry of a Landsat acquisition acquired over path 15 and row 33 near the Chesapeake Bay in Maryland (solar zenith $27.2^{\circ}$, view zenith $3.5^{\circ}$, and relative azimuth $129.1^{\circ}$ ).

As evident in Figs. 3 and 4 (top) the CONUS MODIS atmospheric characterization data have a large amount (typically 50\%) of missing data, primarily due to clouds at the time of MODIS Terra overpass. Consequently, the derived atmospheric correction coefficients have a large number of unknown values (black colors in Fig. 4 top). Consequently, a spatial interpolation of the four atmospheric correction was undertaken. Geostatistical interpolants, such as kriging, are computationally expensive (Pringle et al., 2009), spline based interpolants fit to a large surrounding sample data area but the interpolated values may be outside the range of the sample data, and although inverse distance weighting interpolants are computationally inexpensive they perform poorly for irregular sample data distributions (Shepard, 1968). In this study the natural neighbor interpolation approach was used as it has elegant properties (no tuning parameters, the interpolated values are guaranteed to be within the range of the samples used and will pass through the input samples and are smooth everywhere except at locations of the input samples) (Sibson, 1981). Fig. 4 (bottom) shows the natural neighbor interpolation of the $0.05^{\circ}$ atmospheric correction coefficient data illustrated in Fig. 4 (top). The interpolation preserves the original data and fills the gaps smoothly. For areas of extensive missing data, the interpolation, as with any other method, will be less reliable.

The atmospheric correction coefficients were estimated for each $30 \mathrm{~m} \mathrm{ETM}+$ pixel and band by projecting the $30 \mathrm{~m}$ pixel location into the natural neighbor interpolated data and bilinear resampling the coefficient values from the four neighboring $0.05^{\circ}$ values. Since the natural neighbor interpolated $0.05^{\circ}$ atmospheric correction coefficients may be less accurate, a quality assessment measure is generated as a count of how many (0-4) of the four $0.05^{\circ}$ atmospheric correction coefficient pixels were interpolated. The MODIS-based
Landsat ETM+ surface reflectance was then computed, as for the AERONET atmospheric correction, as:

$\rho^{s}=\frac{\rho^{T O A} / c_{1}-c_{2}}{\left(\left(\rho^{T O A} / c_{1}-c_{2}\right) / c_{3}\right) c_{4}+1}$

where $\rho^{s}$ and $\rho^{T O A}$ are the surface and TOA reflectance respectively, and $c_{1}=T_{d}, c_{2}=\rho_{a t m} / T_{d}, c_{3}=T_{u}$, and $c_{4}=s_{a t m}$ (terms defined for Eq. 1).

\subsection{Accuracy assessment methodology}

The LEDAPS and MODIS-based surface reflectance data for each of the six ETM+ reflective wavelength bands and for all of the 95 $10 \mathrm{~km} \times 10 \mathrm{~km}$ subsets, were compared pixel-by-pixel to the corresponding "truth" AERONET surface reflectance data. Only pixels that were not saturated in the original L1T data, were not labeled as cloudy by either of the ACCA or the classification tree based cloud masks, and were not missing due to the Landsat Scan Line Corrector issue, were considered. Surface and top of atmosphere (TOA) reflectance residuals were derived for each pixel as:

$\Delta \rho_{i, \lambda}^{s}=\left|\rho_{i, \lambda}^{s}-\rho_{i, \lambda, \text { aeronet }}^{s}\right|$

$\Delta \rho_{i, \lambda}^{T O A}=\left|\rho_{i, \lambda}^{T O A}-\rho_{i, \lambda, \text { aeronet }}^{S}\right|$

where $\rho_{i, \lambda}^{S}$ is the LEDAPS or MODIS-based surface reflectance, $\rho^{T O A}{ }_{i, \lambda}$ is the TOA reflectance, and $\rho_{i, \lambda, \text { aeronet }}^{s}$ is the AERONET surface reflectance of pixel $i$ for wavelength $\lambda$, and $\Delta \rho_{i, \lambda}^{s}$ is the surface reflectance residual for the LEDAPS or the MODIS-based atmospherically 
corrected reflectance and $\Delta \rho_{i, \lambda}^{T O A}$ is the TOA reflectance residual. The residuals are defined in unitless reflectance (scaled $0-1$ ). The mean of $\Delta \rho_{i, \lambda}^{S}$ and of $\Delta \rho_{i, \lambda}^{T O A}$ was computed for the LEDAPS and MODISbased methods using all the non-saturated, non-cloudy, nonmissing, pixels in the $9510 \mathrm{~km} \times 10 \mathrm{~km}$ subsets as:

$\bar{\Delta} \rho_{\lambda}^{s}=\left(\sum_{i=1}^{n_{\lambda}} \Delta \rho_{i, \lambda}^{s}\right) / n_{\lambda}$

$\bar{\Delta} \rho_{\lambda}^{T O A}=\left(\sum_{i=1}^{n_{\lambda}} \Delta \rho_{i, \lambda}^{T O A}\right) / n_{\lambda}$

where $\bar{\Delta} \rho_{\lambda}^{s}$ is the mean surface reflectance residual for the LEDAPS or the MODIS-based atmospherically corrected reflectance and $\bar{\Delta} \rho^{T O A}{ }_{\lambda}$ is the mean TOA reflectance residual and $n_{\lambda}$ is the number of nonsaturated, non-cloudy pixels for wavelength $\lambda$.

Similarly, the standard deviation of the residuals $\Delta \rho_{i, \lambda}^{S}$ and $\Delta \rho^{T O A}{ }_{i, \lambda}$ were computed as:

$\sigma_{\Delta \rho_{\lambda}^{s}}=\left(\sum_{i=1}^{n_{\lambda}}\left(\Delta \rho_{i, \lambda}^{s}-\bar{\Delta} \rho_{\lambda}^{s}\right) / n_{\lambda}\right)^{\frac{1}{2}}$

$\sigma_{\Delta \rho^{T O A}{ }_{\lambda}}=\left(\sum_{i=1}^{n_{\lambda}}\left(\Delta \rho_{i, \lambda}^{T O A}-\bar{\Delta} \rho_{\lambda}^{T O A}\right) / n_{\lambda}\right)^{\frac{1}{2}}$

where $\sigma_{\Delta \rho^{s} \lambda}$ and $\sigma_{\Delta \rho^{\text {TOA }} \lambda}$ are the standard deviation of the residuals for the LEDAPS (or MODIS-based) surface reflectance and the TOA reflectance respectively and the other terms are defined earlier.

In order to be able to inter-compare the residuals between spectral bands, mean reflectance normalized residuals were derived as:

$\Delta^{*} \rho_{\lambda}^{s}=\frac{\bar{\Delta} \rho_{\lambda}^{s}}{\bar{\rho}_{\lambda, \text { aeronet }}^{s}}$

$\Delta^{*} \rho_{\lambda}^{T O A}=\frac{\bar{\Delta} \rho_{\lambda}^{T O A}}{\bar{\rho}_{\lambda, \text { aeronet }}^{S}}$

where $\Delta^{*} \rho^{S}$ and $\Delta^{*} \rho^{T O A}{ }_{\lambda}$ are the mean reflectance normalized residual for the LEDAPS (or MODIS-based) surface reflectance and the TOA reflectance respectively, $\bar{\Delta} \rho_{\lambda}^{s}$ and $\bar{\Delta} \rho^{T O A}{ }_{\lambda}$ are defined in Eqs. (6) and (7) respectively, and $\bar{\rho}^{s}$ is the mean of the AERONET corrected reflectance at wavelength $\lambda$ using all the non-saturated, non-cloudy, non-missing, pixels in the $9510 \mathrm{~km} \times 10 \mathrm{~km}$ subsets.

Reflectance scatter plots and simple linear regressions between the TOA ( $y$ axis) and AERONET surface reflectance ( $x$ axis) were generated from all the non-saturated, non-cloudy, non-missing, pixels in the $9510 \mathrm{~km} \times 10 \mathrm{~km}$ subsets to assess the impact of the atmosphere on each ETM+ reflective wavelength band. Then reflectance scatter plots and simple linear regressions between the LEDAPS or MODISbased surface reflectance (y axis) plotted against the AERONET surface reflectance ( $\mathrm{x}$ axis) were used to assess the variability and the bias in the corrected reflectance.

\section{Results}

A total of 7,605,732, 7,605,785, 7,605,338, 7,606,184, 7,605,977, and $7,606,02030 \mathrm{~m}$ pixels in Landsat ETM+ bands $1(0.45-0.52 \mu \mathrm{m}), 2$ (0.53-0.61 $\mu \mathrm{m}), 3(0.63-0.69 \mu \mathrm{m}), 4(0.78-0.90 \mu \mathrm{m}), 5(1.55-1.75 \mu \mathrm{m})$, and $7(2.09-2.35 \mu \mathrm{m})$ respectively that were not saturated in the original L1T data and that were not labeled as cloudy by either of the ACCA or the classification tree based cloud masks were extracted from the 95 $10 \mathrm{~km} \times 10 \mathrm{~km}$ subsets. These numbers differ between bands because the Landsat ETM+ saturation varies spectrally (Markham et al., 2006).
Figs. 5 and 6 show reflectance scatter plots of TOA reflectance versus AERONET surface reflectance (left column), LEDAPS surface reflectance versus AERONET surface reflectance (middle column), and MODIS-based surface reflectance versus AERONET surface reflectance (right column). The solid lines show ordinary least squares linear regression fits of these data. If the LEDAPS or MODIS surface reflectance data were corrected perfectly then they would have equal value as the AERONET surface reflectance data and all points in the middle and right columns of Figs. 5 and 6 would fall on the dotted 1:1 lines. For the LEDAPS and MODIS-based surface reflectance plots (middle and right columns) the regression lines are constrained to pass through the origin to examine which method provides generally closest agreement with the AERONET surface reflectance (i.e. slopes closer to unity). The frequency of occurrence of the nearly 8 million reflectance values is shown with a rainbow color scale (red most frequent, purple least frequent). The regression coefficients and goodness of fit $\left(R^{2}\right)$ values are shown on the figures - all of the regressions and $R^{2}$ values were significant at the $99 \%$ confidence level.

Fig. 5 shows plots for the three Landsat ETM+ visible wavelength bands: band 1 (blue, $0.45-0.52 \mu \mathrm{m}$ ) top row, band 2 (green, $0.53-0.61 \mu \mathrm{m}$ ) middle row, and band 3 (red $0.63-0.69 \mu \mathrm{m}$ ) bottom row. These are the shortest wavelength bands and atmospheric scattering is expected to be greatest at shorter wavelength. This is evident in that the slopes of the regression lines for the blue, green and red TOA reflectance against the AERONET surface reflectance are 0.74 , 0.79 and 0.86 respectively (Fig. 5, first column). These three regression slopes are less than unity because Rayleigh and aerosol backscatter into the sensor adds to the TOA signal at low reflectance ranges and aerosol absorption attenuates the TOA signal at higher reflectance. The effect of the LEDAPS and the MODIS-based atmospheric corrections is to provide surface reflectance that is closer to the AERONET surface reflectance (Fig. 5, middle and right columns), with both methods providing surface reflectance estimates that overall slightly underestimate the AERONET surface reflectance (regression slopes varying from 0.947 to 0.993). The MODIS-based surface reflectance shows slightly better or comparable linear relationships with the AERONET surface reflectance (higher $\mathrm{R}^{2}$ values and slopes closer to unity) than the LEDAPS surface reflectance in the green and red bands, but a slightly worse linear relationship in the blue band.

Fig. 6 shows plots for the longer wavelength Landsat ETM+ bands: band 4 (NIR, $0.78-0.90 \mu \mathrm{m})$ top row, band 5 (middle-IR, 1.55-1.75 $\mu \mathrm{m}$ ) middle row, and band 7 (middle-IR, 2.09-2.35 $\mu \mathrm{m}$ ) bottom row. In this longer-wavelength range, the effect of the atmosphere is less apparent and the TOA reflectance is about 0.92 , 0.95 and 0.89 of the surface reflectance respectively (Fig. 6, first column). Consequently the difference between the MODIS-based and LEDAPS surface reflectance is less apparent although for all three bands the MODIS-based surface reflectance shows slightly better linear relationships with the AERONET surface reflectance (slopes closer to unity) than the LEDAPS surface reflectance (Fig. 6, middle and right columns). Both methods provide surface reflectance estimates that slightly overestimate the AERONET surface reflectance, particularly the LEDAPS results (regression slopes varying from 1.036 to 1.054 ), compared to the MODIS results (regression slopes varying from 1.007 to 1.014). It is unclear what the causes of these biases are.

Table 1 summarizes, for each Landsat ETM + reflective wavelength band, the mean LEDAPS and MODIS-based surface reflectance residuals (Eq. 6) and also for reference the mean TOA reflectance residuals (Eq. 7). The standard deviations of these residuals (Eqs. 8 and 9) are summarized in parentheses. The mean TOA reflectance residuals show the significantly increasing impact of the atmosphere with decreasing wavelength. For example, in the ETM + blue band (0.45-0.52 $\mu \mathrm{m})$ the mean TOA reflectance residual is 0.0669 , about two orders of magnitude greater than the mean LEDAPS or mean MODIS-based blue band surface reflectance residuals. 

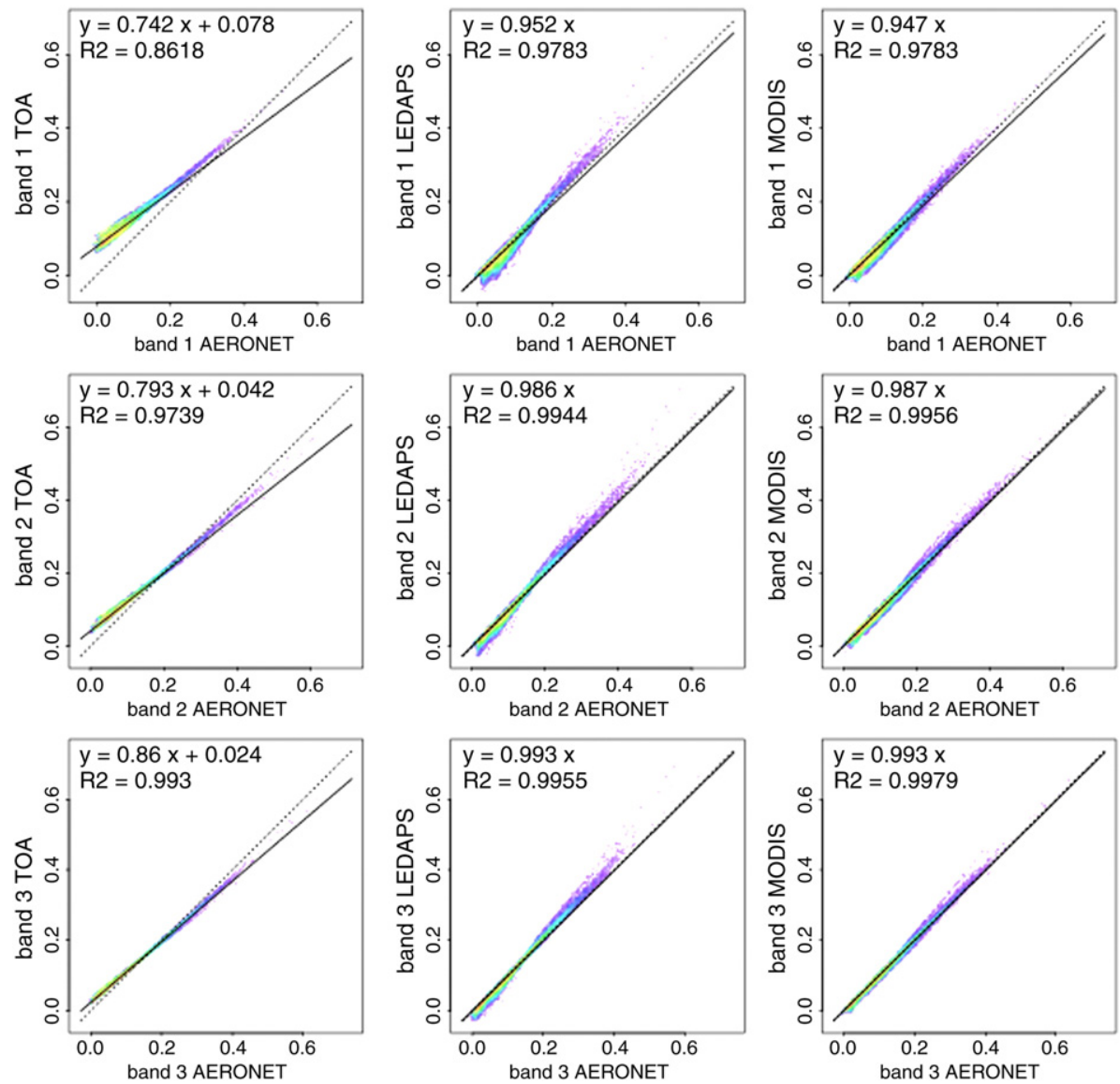

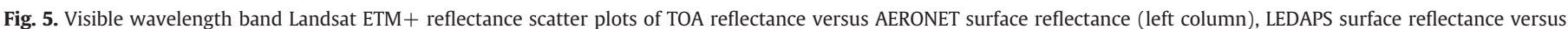

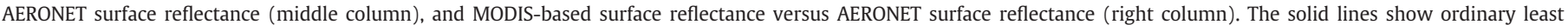

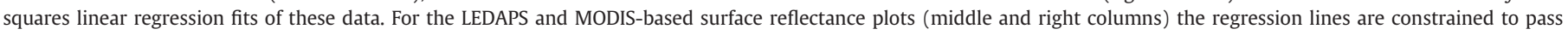

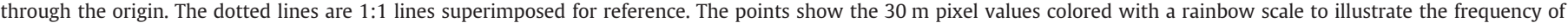
the reflectance values (red most frequent, purple least frequent).

The most striking result apparent in Table 1 is that the mean and standard deviation of the MODIS-based surface reflectance residuals are smaller than those of the LEDAPS surface reflectance residuals in all the Landsat ETM+ bands except for the green and blue bands. The green band mean residuals are the same for the LEDAPS and MODIS-based methods but the MODIS residuals have smaller standard deviation. The spectral variation in the LEDAPS and MODISbased surface reflectance residuals is complex and is driven by the spectral variation in atmospheric contamination (which generally decreases with wavelength) and also by the spectral properties of the surface, whereby for example, healthy vegetation has low red reflectance and high near-infrared reflectance. To investigate this, the mean reflectance normalized residuals (Eqs. 10 and 11), i.e., the mean residuals expressed as percentages of the mean AERONET surface reflectance, were computed and are summarized in Table 2.

In the blue band the LEDAPS and MODIS-based mean reflectance normalized residuals are $11.8 \%$ and $13.5 \%$ respectively (Table 2 ). This suggests that both the LEDAPS and MODIS-based methods provide unreliable blue band atmospheric correction, which is a known atmospheric correction issue due to the high atmospheric sensitivity at this wavelength (Vermote \& Kotchenova, 2008) and is evident in that the mean reflectance normalized TOA residual is nearly $150 \%$ (Table 2, right column). Both methods provide green band mean reflectance normalized residuals of $5.7 \%$ which is nearly seven times less than the mean green band reflectance normalized TOA residual (39.9\%). In the red band the LEDAPS mean reflectance normalized residual $(5.9 \%)$ is greater than that of MODIS $(4.2 \%)$ and both mean residuals are about four times smaller than the mean TOA residual (19.3\%). In the longer wavelength bands the LEDAPS mean reflectance normalized residuals are more than two to more than three times greater than the MODIS-based mean reflectance normalized residuals.

The results summarized in Tables 1 and 2 indicate that the MODISbased atmospheric correction approach is generally more accurate and robust than the LEDAPS approach. For all the Landsat ETM+ bands (Table 2), the TOA mean reflectance normalized residuals are significantly greater than the MODIS mean reflectance normalized residuals, illustrating the need for Landsat atmospheric correction. Similarly, the TOA mean reflectance normalized residuals are greater than the LEDAPS mean reflectance normalized residuals, except for the near-infrared Landsat band 4 which has a $4.8 \%$ LEDAPS mean reflectance normalized residual compared to the $4.1 \%$ TOA band 4 mean reflectance normalized residual. This does not mean that atmospheric correction is generally not needed for Landsat band 4 , and we note that band 4 is also the band with the smallest relative difference between MODIS mean reflectance normalized residuals compared to the TOA mean reflectance normalized residual. It is well established that near-infrared wavelengths are particularly susceptible to water vapor contamination (Vermote \& Kotchenova, 2008; Vermote \& Saleous, 2006) and so it is likely that this LEDAPS band 4 discrepancy may be due to spatial and/or temporal resolution mismatches, for certain Landsat acquisitions, between the atmospheric water vapor content at the time of Landsat overpass and the $2.5^{\circ}$ six hour NCEP/NCAR water vapor data used by the LEDAPS correction approach. The 

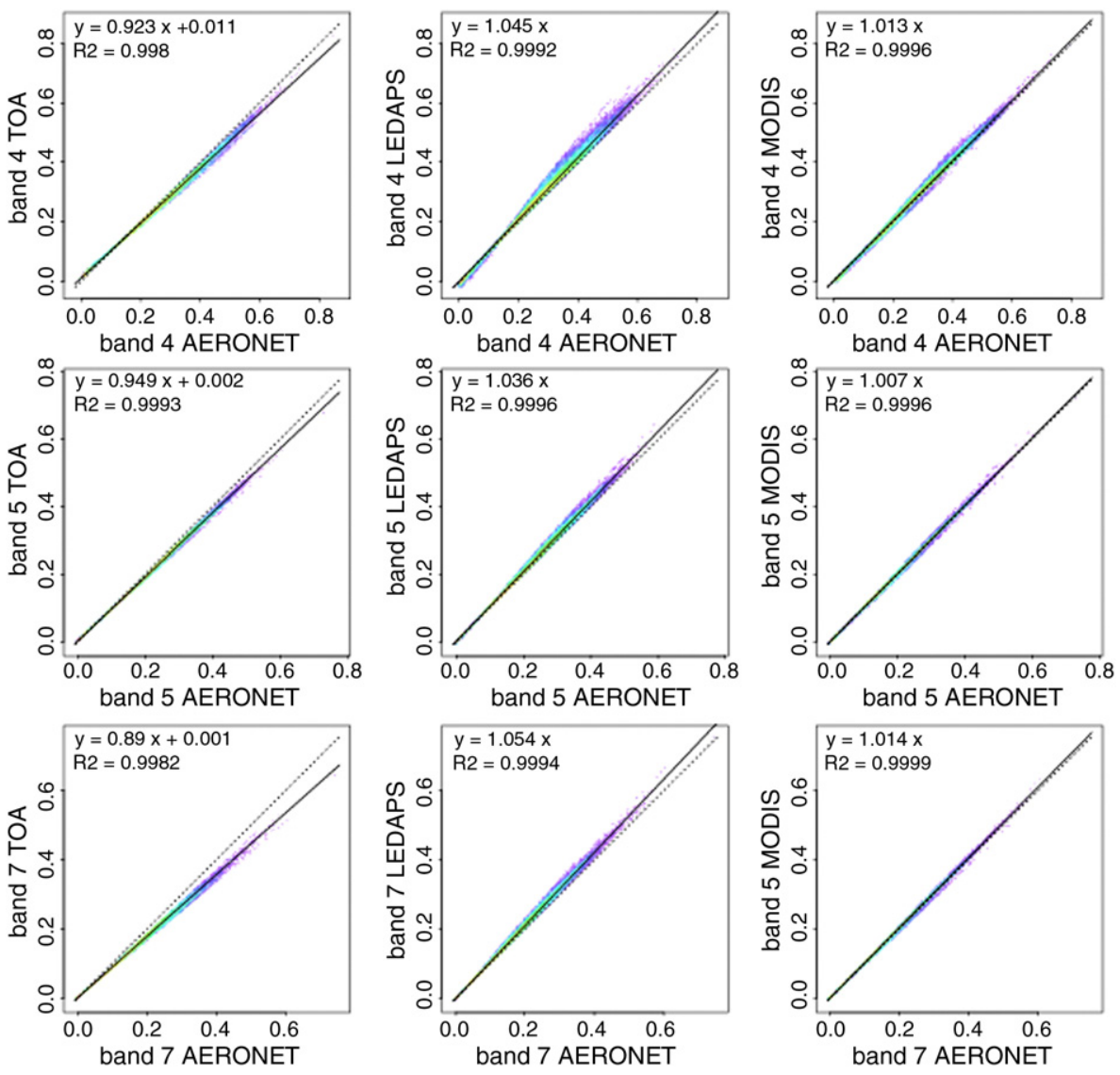

Fig. 6. Infrared reflective wavelength band Landsat ETM+ reflectance scatter plots (as Fig. 5).

MODIS approach uses $0.05^{\circ}$ water vapor retrieved from the MODIS overpass which is not only of higher spatial resolution but also nearly coincident with the Landsat acquisition time. In addition, however, the way that the different atmospheric characterization data are interpolated to match Landsat acquisition times and locations is also likely to be influential. This is demonstrated in Fig. 7 which shows a spectral plot of the mean MODIS-based surface reflectance residuals (Eq. 6) considering all the $30 \mathrm{~m}$ pixels (open symbols, same results as Table 1 ) and considering only $30 \mathrm{~m}$ pixels where no $0.05^{\circ}$ correction coefficients were natural neighbor interpolated (filled symbols). For the almost 8 million $30 \mathrm{~m}$ pixels used in this analysis, approximately $38 \%$ had at least one natural neighbor interpolated $0.05^{\circ}$ correction coefficient pixel. As expected, the mean MODIS-based surface reflectance residuals illustrated in Fig. 7 are consistently higher, by about $5-9 \%$ for ETM + bands 1-4, and similar in ETM+ band 5 , when no natural neighbor interpolated values are used.

Table 1

The mean residuals of the LEDAPS surface reflectance and the MODIS-based surface reflectance (Eq. 6), and the mean residuals of the TOA reflectance (Eq. 7), for each Landsat ETM+ reflective wavelength band. The standard deviations of the residuals are shown in parenthesis.

\begin{tabular}{llll}
\hline $\begin{array}{l}\text { Band } \\
\text { reflectance } \bar{\Delta} \rho_{\lambda}^{s} \text { and } \\
\sigma_{\Delta \rho^{s} \lambda}\end{array}$ & $\begin{array}{l}\text { MODIS-based surface } \\
\text { reflectance } \bar{\Delta} \rho_{\lambda}^{s} \text { and } \sigma_{\Delta \rho^{g} \lambda}\end{array}$ & $\begin{array}{l}\text { TOA reflectance } \\
\bar{\Delta} \rho^{\text {TOA }}{ }_{\lambda} \text { and } \sigma_{\Delta \rho^{\text {TOA }} \lambda}\end{array}$ \\
\hline 1 & $0.0053(0.0058)$ & $0.0060(0.0052)$ & $0.0669(0.0111)$ \\
2 & $0.0039(0.0043)$ & $0.0039(0.0034)$ & $0.0276(0.0086)$ \\
3 & $0.0042(0.0039)$ & $0.0030(0.0026)$ & $0.0138(0.0072)$ \\
4 & $0.0100(0.0079)$ & $0.0041(0.0039)$ & $0.0085(0.0063)$ \\
5 & $0.0056(0.0049)$ & $0.0015(0.0015)$ & $0.0068(0.0040)$ \\
7 & $0.0051(0.0051)$ & $0.0016(0.0016)$ & $0.0105(0.0079)$ \\
\hline
\end{tabular}

Conversely, the mean MODIS-based surface reflectance residuals for ETM + band 7 are higher by $8 \%$ when no natural neighbor interpolated values are used. The results in Fig. 7 suggest the utility of providing a quality assessment band with the MODIS-based atmospheric correction results that count, for example, how many of the four $0.05^{\circ}$ MODIS atmospheric correction coefficient pixels were bilinearly interpolated in the generation of a $30 \mathrm{~m} \mathrm{ETM}+$ surface reflectance value.

It is beyond the scope of this paper to analyze the impact of the atmospheric correction methodologies on higher level products that may be derived from Landsat surface reflectance. However, the Normalized Difference Vegetation Index (NDVI), defined as the nearinfrared minus the red reflectance divided by their sum, is widely used and, for this reason, is included as a WELD product band (Roy et al., 2010). To examine the impact on NDVI of the two atmospheric correction approaches, NDVI residuals and mean residuals were computed as Eqs. (4) and (6) respectively (but using the NDVI instead of

Table 2

The mean AERONET surface reflectance, and the mean reflectance normalized residuals of the LEDAPS surface reflectance and the MODIS-based surface reflectance (Eq. 10), and the mean reflectance normalized residuals of the TOA reflectance (Eq. 11).

\begin{tabular}{|c|c|c|c|c|}
\hline Band & $\begin{array}{l}\text { Mean AERONET } \\
\text { surface reflectance } \\
\left(\bar{\rho}_{\lambda, \text { aeronet }}^{s}\right)\end{array}$ & $\begin{array}{l}\text { Mean } \\
\text { reflectance } \\
\text { normalized } \\
\text { residual for } \\
\text { LEDAPS }{ }_{?}\left(\Delta^{*} \rho_{\lambda}^{S}\right)\end{array}$ & $\begin{array}{l}\text { Mean reflectance } \\
\text { normalized } \\
\text { residual for } \\
\text { MODIS-based } \\
\left(\Delta^{*} \rho_{\lambda}^{S}\right)\end{array}$ & $\begin{array}{l}\text { Mean } \\
\text { reflectance } \\
\text { normalized } \\
\text { residual for } \\
\operatorname{TOA}\left(\Delta^{*} \rho^{T O A}\right)\end{array}$ \\
\hline 1 & 0.0447 & $11.8 \%$ & $13.5 \%$ & $149.7 \%$ \\
\hline 2 & 0.0692 & $5.7 \%$ & $5.7 \%$ & $39.9 \%$ \\
\hline 3 & 0.0714 & $5.9 \%$ & $4.2 \%$ & $19.3 \%$ \\
\hline 4 & 0.2092 & $4.8 \%$ & $2.0 \%$ & $4.1 \%$ \\
\hline 5 & 0.1550 & $3.6 \%$ & $1.0 \%$ & $4.4 \%$ \\
\hline 7 & 0.0986 & $5.2 \%$ & $1.6 \%$ & $10.6 \%$ \\
\hline
\end{tabular}




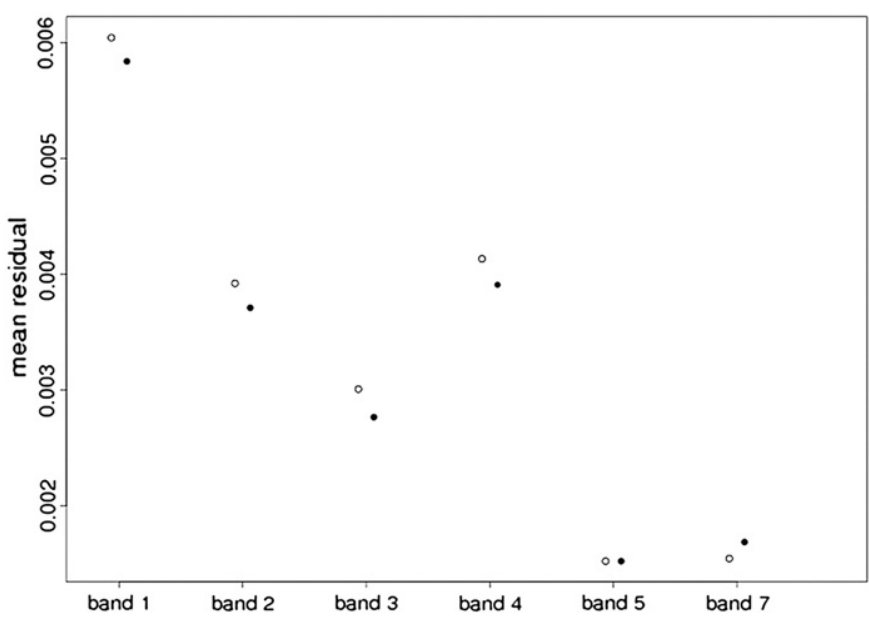

Fig. 7. Spectral plot of the mean MODIS-based surface reflectance residuals (Eq. 6) considering all $\sim 8$ million 30 m pixels (open symbols, same results as Table 1 ) and considering only the $\sim 5$ million $30 \mathrm{~m}$ pixels where no $0.05^{\circ}$ correction coefficients were natural neighbor interpolated (filled symbols).

spectral reflectance in these formulae), and were then normalized with respect to the mean AERONET NDVI as Eq. (10), using NDVI derived from the AERONET, LEDAPS and MODIS-based bands 3 and 4 surface reflectance data. The mean NDVI normalized residuals were $3.1 \%$ and $6.3 \%$ for the MODIS-based method and the LEDAPS method respectively, i.e., similar to the maximum of the normalized bands 3 and 4 surface reflectance residuals for each method reported in Table 2. For reference, the mean TOA NDVI normalized residual, computed as Eqs. (5), (7) and (11) using NDVI derived from TOA surface bands 3 and 4 reflectance, was 16.8\%. Evidently the impact of atmospheric correction on NDVI is quite important which has been observed by many other researchers (Miura et al., 2001; Slater \& Jackson, 1982; Teillet et al., 1997).

\section{Discussion and conclusions}

This study compared the atmospheric correction accuracy of the Landsat Ecosystem Disturbance Adaptive Processing System (LEDAPS) and a new MODIS-based atmospheric correction method. A comprehensive validation was undertaken. A total of nearly 8 million Landsat ETM+ pixels were atmospherically corrected using the two methods and compared with AERONET corrected equivalents. These data were extracted across the conterminous United States from 82 Landsat ETM+ acquisitions sensed from December 2007 to November 2008 at 26 AERONET sites. The results indicate that the MODIS-based method has overall higher accuracy than the LEDAPS method for all the ETM+ bands except the green band, where the results for the two methods are comparable, and the blue band where both the LEDAPS and MODIS-based atmospheric correction methods performed less reliably. In the longer wavelength reflective bands the LEDAPS atmospheric correction method performed less reliably than the MODIS-based method by a factor of about two to three. The accuracy level provided by the MODIS-based Landsat ETM+ atmospheric correction method is comparable to that provided by the operational MODIS atmospheric correction algorithm implemented over a diverse range of surfaces and atmospheres (Vermote \& Kotchenova, 2008; http://modis-sr.ltdri.org/). This degree of agreement is not surprising because, although MODIS has superior spectral and radiometric characteristics compared to the Landsat ETM+, at scan edge the MODIS atmospheric path length is nearly double the $\mathrm{ETM}+$ path length due to the difference in the field of view of the MODIS $\left(110^{\circ}\right)$ and Landsat ETM+ $\left(15^{\circ}\right)$ instruments.

The LEDAPS and the MODIS-based methods both use the 6SV radiative transfer code, but differ in the way that they characterize the atmosphere. The MODIS-based method uses MODIS Terra derived aerosol optical thickness, aerosol type and water vapor to atmospherically correct Landsat ETM + acquisitions in each coincident orbit. The LEDAPS method derives the aerosol optical thickness from each Landsat acquisition and independently corrects each image assuming a fixed continental aerosol type, and uses $2.5^{\circ}$ spatial resolution water vapor defined every $6 \mathrm{~h}$ from the National Centers for Environmental Prediction (NCEP) and the National Center for Atmospheric Research (NCAR). The sensitivity of 6S to different atmospheric parameterizations is non-linear and difficult to extrapolate to all combinations of characterizations (Vermote \& Saleous, 2006). The MODIS Terra instrument senses a much larger swath $(\sim 2300 \mathrm{~km})$ than the ETM+ $(\sim 185 \mathrm{~km})$ which provides more opportunities for dense dark vegetation (DDV) target identification and the improved version of the MODIS DDV approach allows for brighter vegetation targets for aerosol retrieval. Further, MODIS has superior spectral and radiometric characteristics compared to the Landsat ETM+ instrument and the MODIS near-infrared bands can be used for water vapor retrieval (Vermote \& Kotchenova, 2008). For these reasons, the MODIS-based method should provide more reliable atmospheric characterization than the LEDAPS approach. However, the MODIS spatial resolution $(500 \mathrm{~m})$ is much coarser than the ETM + spatial resolution $(30 \mathrm{~m})$ at the wavelengths used for DDV target identification, and the MODIS atmospheric characterization describes the atmosphere approximately 25 min after the Landsat ETM+ overpass. Consequently, for example, small and spatially fragmented DDV targets less than $500 \mathrm{~m}$ in dimension and dynamic aerosols may be better defined from the ETM + acquisition itself under the LEDAPS approach. In addition, the way that the different atmospheric characterization data are interpolated to match Landsat acquisition times and locations is likely to influence the atmospheric correction accuracy. Sensitivity analyses are required to investigate the results reported in this paper in more detail, the multiple influencing factors behind them, and the impacts of error in surface reflectance on higher level derived Landsat products and on applications such as land cover characterization. Certainly however, improved atmospheric characterization at the time of satellite overpass will result in more reliable radiative transfer based atmospheric corrections. For this reason further work to investigate a fusion of Landsat imagebased aerosol retrievals and MODIS-based atmospheric characterization data is also recommended.

Finally, we note that although the MODIS-based atmospheric correction has generally better performance than the image-based LEDAPS approach, the LEDAPS approach can be applied to the historic Landsat Thematic Mapper archive (available since 1982) and also to future Landsat sensors regardless of the availability of the next generation of operational moderate spatial resolution global polar-orbiting remote sensing systems (Roy et al., 2008; Wulder et al., 2011).

\section{Acknowledgments}

The LEDAPS project was funded by NASA's Terrestrial Ecology Program. This Web-enabled Landsat Data (WELD) project is funded by NASA's Making Earth System Data Records for Use in Research Environments (MEaSUREs) program, grant number NNX08AL93A. The U.S. Landsat project management and staff are thanked for provision of the Landsat ETM+ data. The AERONET PIs and their staff are thanked for establishing and maintaining the CONUS AERONET sites used in this study.

\section{References}

Chander, G., Markham, B. L., \& Helder, D. L. (2009). Summary of current radiometric calibration coefficients for Landsat MSS, TM, ETM+, and EO-1 ALI sensors. Remote Sensing of Environment, 113(2009), 893-903.

Chavez, P. S., Jr. (1996). Image-based atmospheric corrections - Revisited and improved. Photogrammetric Engineering and Remote Sensing, 62(9), 1025-1036. 
Dubovik, O., Holben, B., Eck, T. F., Smirnov, A., Kaufman, Y. J., King, M. D., et al. (2002). Variability of absorption and optical properties of key aerosol types observed in worldwide locations. Journal of Atmospheric Science, 59, 590-608.

Holben, B. N., Eck, T. F., Slutsker, I., Tanré, D., Buis, J. P., Setzer, A., et al. (1998). AERONET A federated instrument network and data archive for aerosol characterization. Remote Sensing of Environment, 66(1), 1-16.

Irish, R. I., Barker, J. L., Goward, S. N., \& Arvidson, T. (2006). Characterization of the Landsat-7 ETM+ automated cloud-cover assessment (ACCA) algorithm. Photogrammetric Engineering and Remote Sensing, 72(10), 1179-1188.

Kaufman, Y. J., \& Sendra, C. (1988). Algorithm for automatic corrections to visible and near IR satellite imagery. International Journal of Remote Sensing, 9, 1357-1381.

Kaufman, Y. J., Tanre, D., Remer, L. A., Vermote, E. F., Chu, A., \& Holben, B. N. (1997). Operational remote sensing of tropospheric aerosol over the land from EOSMODIS. Journal of Geophysical Research-Atmosphere, 102(14), 17051-17068.

Kotchenova, S., Vermote, E., Matarrese, R., \& Klemm, F., Jr. (2006). Validation of a vector version of the $6 \mathrm{~S}$ radiative transfer code for atmospheric correction of satellite data. Part I: Path radiance. Applied Optics, 45, 6762-6774.

Lee, D. S., Storey, J. C., Choate, M. J., \& Hayes, R. (2004). Four years of Landsat-7 on-orbit geometric calibration and performance. IEEE Transactions on Geoscience and Remote Sensing, 42, 2786-2795.

Liang, S., Fang, H., \& Chen, M. (2001). Atmospheric correction of Landsat ETM+ land surface imagery: I. Methods. IEEE Transactions on Geoscience and Remote Sensing, 39, 2490-2498.

Markham, D., Goward, G., Arvidson, T., Barsi, J., \& Scaramuzza, P. (2006). Landsat-7 long-term acquisition plan radiometry - Evolution over time. Photogrammetric Engineering and Remote Sensing, 72, 1129-1135.

Masek, J. G., Vermote, E. F., Saleous, N. E., Wolfe, R., Hall, F. G., Huemmrich, K. F., et al. (2006). A Landsat surface reflectance dataset for North America, 1990-2000. IEEE Transactions on Geoscience and Remote Sensing Letters, 3(1), 68-72.

Miura, T., Huete, A. R., Yoshioka, H., \& Holben, B. N. (2001). An error and sensitivity analysis of atmospheric resistant vegetation indices derived from dark target-based atmospheric correction. Remote Sensing of Environment, 78, 284-298.

Ouaidrari, H., \& Vermote, E. F. (1999). Operational atmospheric correction of Landsat TM data. Remote Sensing of Enviroment, 70, 4-15.

Pringle, M. J., Schmidt, M., \& Muir, J. S. (2009). Geostatistical interpolation of SLC-off Landsat ETM+ images. ISPRS Journal of Photogrammetry and Remote Sensing, 64 (6), 654-664.
Roy, D. P., Ju, J., Kline, K., Scaramuzza, P. L., Kovalskyy, V., Hansen, M. C., et al. (2010) Web-enabled Landsat data (WELD): Landsat ETM+ composited mosaics of the conterminous United States. Remote Sensing of Environment, 114, 35-49.

Roy, D. P., Ju, J., Kommareddy, I., Hansen, M., Vermote, E., Zhang, C., et al. (2011). Web Enabled Landsat data (WELD) products - Algorithm theoretical basis document, February 2011. http://globalmonitoring.sdstate.edu/projects/weld/WELD_ATBD.pdf

Roy, D. P., Ju, J., Lewis, P., Schaaf, C., Gao, F., Hansen, M., et al. (2008). Multi-tempora MODIS-Landsat data fusion for relative radiometric normalization, gap filling and prediction of Landsat data. Remote Sensing of Environment, 112, 3112-3130.

Shepard, D. (1968). A two-dimensional interpolation function for irregularly-spaced data. Proceedings of the 1968 ACM National Conference (pp. 517-524)., doi: $10.1145 / 800186.810616$

Sibson, R. (1981). A brief description of natural neighbor interpolation (chapter 2). In V. Barnett (Ed.), Interpreting multivariate data (pp. 21-36). Chichester: John Wiley.

Slater, P. N., \& Jackson, R. D. (1982). Atmospheric effect on radiation reflected from soil and vegetation as measured by orbiting sensors using various scanning directions. Applied Optics, 21, 3923-3931.

Song, C., \& Woodcock, C. E. (2003). Monitoring forest succession with multitempora Landsat images: Factors of uncertainty. IEEE Transactions on Geoscience and Remote Sensing, 41(11), 2557-2567.

Teillet, P., Staenz, K., \& Williams, D. (1997). Effects of spectral, spatial, and radiometric characteristics on remote sensing vegetation indices of forested regions. Remote Sensing of Environment, 61, 139-149.

Vermote, E. F., El Saleous, N., \& Justice, C. (2002). Atmospheric correction of the MODIS data in the visible to middle infrared: First results. Remote Sensing of Environment, 83(1-2), 97-111.

Vermote, E. F., \& Kotchenova, S. (2008). Atmospheric correction for the monitoring of land surfaces. Journal of Geophysical Research, 113, D23S90, doi:10.1029/2007JD009662.

Vermote, E. F., \& Saleous, N.Z. (2006). Operational atmospheric correction of MODIS visible to middle infrared land surface data in the case of an infinite Lambertian target. In J. J Qu, W. Gao, M. Kafatos, R. E. Murphy, \& V. V. Salomonson (Eds.), Earth Science Satellite Remote Sensing, Science and Instruments, vol. 1, ch. 8. (pp. 123-153): Springer.

Woodcock, C. E., Allen, A. A., Anderson, M., Belward, A. S., Bindschadler, R., Cohen, W. B. et al. (2008). Free access to Landsat imagery. Science, 320, 1011.

Wulder, M. A., White, J. C., Masek, J. G., Dwyer, J., \& Roy, D. P. (2011). Continuity of Landsat observations: Short term considerations. Remote Sensing of Environment, $115,747-751$. 